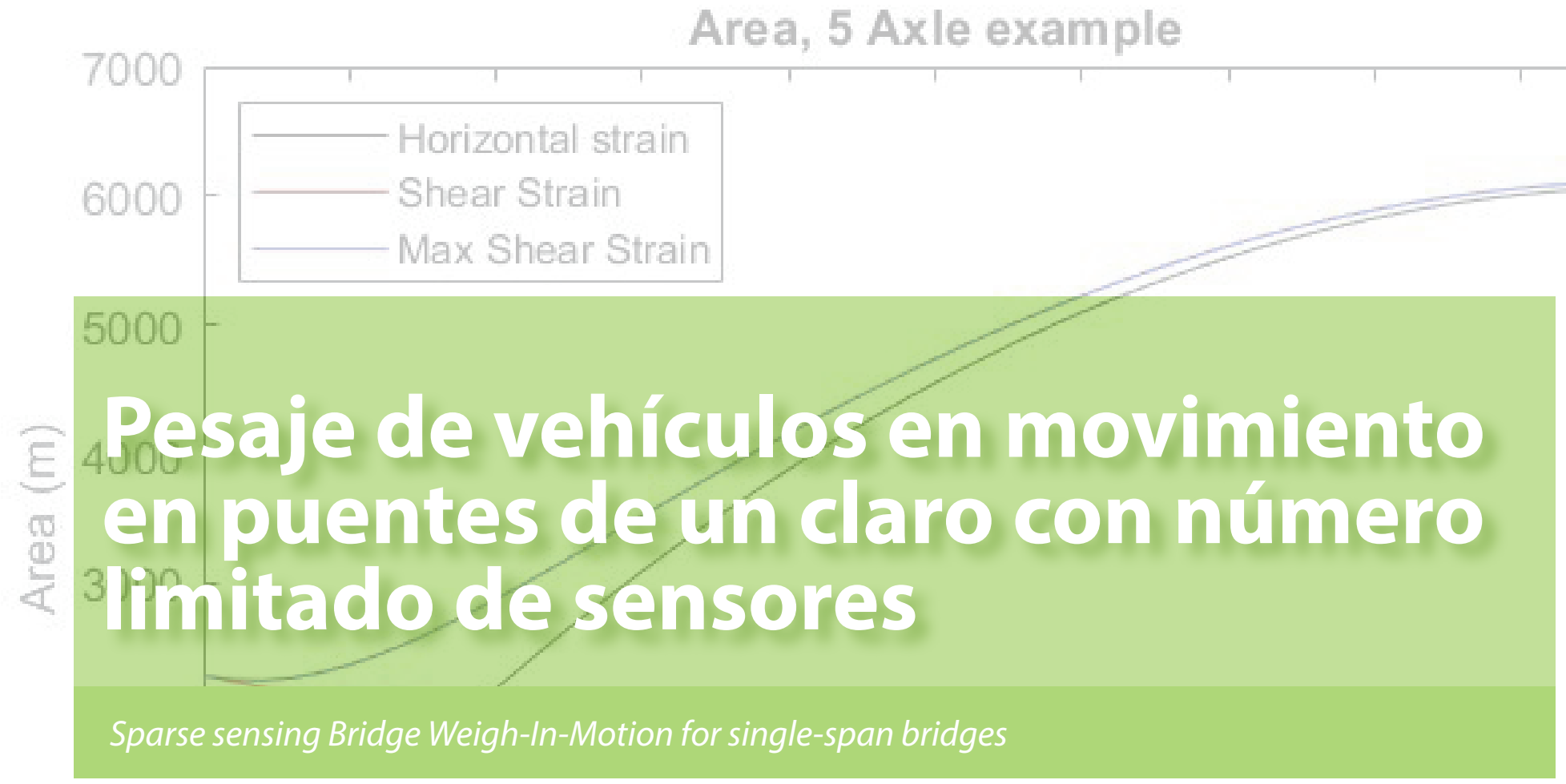

Ing. Pablo Aguero Barrantes, M.Sc.

Estudiante de Doctorado en Ingeniería Civil,

Universidad de Connecticut, Connecticut, Estados Unidos,

pablo.aguero_barrantes@uconn.edu

Ing. Sergio Lobo Aguilar, Ph.D.

Profesor de la Escuela de Ingeniería Civil,

Universidad de Costa Rica, San José, Costa Rica,

sergio.lobo@ucr.ac.cr
Ing. Richard E. Christenson, Ph.D.

Profesor del Departamento de Ingeniería Civil y Ambiental,

Universidad de Connecticut, Connecticut, Estados Unidos,

richard.christenson@uconn.edu

Fecha de recepción: 25 de marzo 2021 / Fecha de aprobación: 3 de noviembre 2021

Índices y Bases de Datos:

latindex ucrindex

\section{- Dialnet DOA}

\section{Ulbiblat ERIHPLUS}

Políticas de Uso:

\section{(c)}

Revista Métodos y Materiales por LanammeUCR se distribuye bajo: Licencia Creative Commons Atribución-NoComercialSinDerivar 4.0 Internacional. ISSN electrónico: 2215-4558 


\title{
Pesaje de vehículos en movimiento en puentes de un claro con número limitado de sensores
}

\author{
Sparse sensing Bridge Weigh-In-Motion for single-span bridges
}

Ing. Pablo Aguero Barrantes, M.Sc.

Estudiante de Doctorado en Ingeniería Civil, Universidad de Connecticut, Connecticut, Estados Unidos, pablo.aguero_barrantes@uconn.edu

Ing. Sergio Lobo Aguilar, Ph.D.

Profesor de la Escuela de Ingeniería Civil, Universidad de Costa Rica, San José, Costa Rica, sergio.lobo@ucr.ac.cr
Ing. Richard E. Christenson, Ph.D.

Profesor del Departamento de Ingeniería Civil y Ambiental, Universidad de Connecticut, Connecticut, Estados Unidos, richard.christenson@uconn.edu

Fecha de recepción: 25 de marzo 2021 / Fecha de aprobación: 3 de noviembre 2021

\section{RESUMEN}

En las economías emergentes, la implementación de la Gestión de Infraestructura del Transporte es una necesidad imperante. Con el propósito de utilizar de la forma más eficiente posible los limitados recursos disponibles, la tecnología surge como un aliado estratégico en dicho objetivo. Con el fin de preservar los pavimentos y puentes, diferentes metodologías han sido desarrolladas para la detección de vehículos con sobrepeso. En el presente artículo se presenta la implementación y validación del pesaje de vehículos en movimiento mediante la instrumentación de un puente en servicio ubicado en Costa Rica, con una cantidad reducida de sensores. Se utilizó el enfoque basado en áreas de influencia de ondas de respuesta de deformaciones unitarias. Dada la distribución de los sensores, minimizando los requisitos de instrumentación, se utilizaron dos tipos de deformación unitaria: horizontal y cortante. Dos camiones de calibración fueron utilizados como referencia y luego se procedió a estimar el peso del tráfico aleatorio, para confrontar dichos resultados con los datos de la estación de pesaje estática más cercana.

PALABRAS CLAVE: Pesaje en Movimiento con puentes (BWIM), puentes, deformaciones unitarias, Deformaciones Unitarias de Corte, Gestión, Peso Bruto Vehicular.

\section{ABSTRACT}

In emerging economies, the implementation of Transportation Infrastructure Management is a prevailing need. In order to use limited available resources in the most efficient way, technology emerges as a strategic ally. For the purpose of pavement and bridge preservation, different methodologies have been developed for the detection of overweight vehicles. This article presents the implementation and validation of Bridge Weigh-In-Motion (BWIM) located in Costa Rica through the instrumentation of an in-service highway bridge with minimal instrumentation requirements. The approach used was based on the concept of influence area from strain response time histories. Given the location of the sensors near the bridge abutment to reduce installation requirements, two types of strain responses were analyzed based on horizontal strain and shear strain in order to define quantity and location of sensors for possible implementations. Two calibration trucks were used as reference for calibration and the weight from over 90 trucks were estimated and compared to static measurements from a nearby permanent static weigh station.

KEYWORDS: Bridge Weigh-In-Motion (BWIM), Bridges, Unit Strains, Shear Strains, Management, Gross-Vehicle Weight (GVW). 


\section{INTRODUCTION}

In developing countries, like Costa Rica, cost effective solutions through the Transportation Infrastructure Management (TIM) approach can help to best invest scarce resources (Sanabria-Sandino \& Barrantes-Jiménez, et al, 2019). Pavement Management Systems (PMS) and Bridge Management Systems (BMS), as implemented tools in TIM, use high-quality data to support decisions. Data regarding the individual bridge structural condition and the functional characteristics of the traffic crossing the bridge feed continuously to large databases to provide quality information for bridge managers to make efficient decisions. Examples of this data are the number and the gross vehicle weight (GVW) of heavy truck traffic, which can be used for future structural design of bridges and pavements. Weigh stations are the traditional way to collect data for obtaining such information.

In Costa Rica's particular case, five permanent weigh stations service the entire country. According to estimations (Allen et al., 2014) between 14 and 23 new weigh stations are required with an individual construction and equipment cost around US $\$ 4.0$ million (CONAVI, 2017), in addition to the potential cost of the land. When these stations are under service, the operation and maintenance cost will further increase the overall cost of installing new permanent weigh stations. The high initial, operational and maintenance costs are not the only issue for traditional weigh stations. The time required to weigh each vehicle can result in long queues that can interrupt the traffic flow, resulting in safety issues as trucks are stopped on the main line of the road and overweight trucks potentially avoid the weigh station by not pulling into the station.

In this context, the concept of smart infrastructure, specifically Weigh-In-Motion (WIM) technology, is an alternative approach that can provide valuable data at lower cost and increased safety. The original concept of WIM systems, called Pavement Weigh-In-Motion (PWIM), is to place sensors directly into the pavement, measuring vehicle properties while they cross over the sensors themselves. Although these systems are advantageous, their installation requires lane closures, putting workers in potentially dangerous situations adjacent to moving traffic; and damages the pavement by cutting or excavating for sensor installation. Further, the dynamic interaction between the pavement and the truck can significantly affect the error in the results (Wall et al. 2009).

Another WIM approach, suggested initially by Moses in 1979 and known as Bridge Weigh-In-Motion (BWIM), is to instrument the girders of a bridge and use the bridge itself as a calibrated sensor. This approach, installing relatively inexpensive sensors underneath the bridge, provides a costeffective solution without the costs and risks to construction workers, or damage to the pavement associated with PWIM systems. There are a variety of methods for post-processing the sensor data provided by BWIM systems, for example: influence areas (Ojio \& Yamada, 2002), orthotropic algorithms (O’Brien et al., 2008), genetic algorithms (Muñoz et al., 2011), neural networks (Hitchcock et al., 2012), genetic algorithms and wavelets (Lechner et al., 2013), deconvolution in the frequency domain (Froseth, et al., 2017), regularized least-squares QR Decomposition (Zheng, et al., 2019), among others.

In this paper, a BWIM implementation on a highway bridge in Guanacaste, Costa Rica, is presented. In order to ease the installation of the sensors, a close-to-end location was selected on the bridge girders. In contrast, the traditional approach is to place the sensor near the midspan of the bridge, where the horizontal strain should be largest, however, it brings higher installation and maintenance costs, due to scaffolding or a bucket truck and possible longer cable lengths. The influence area approach was used, with two post-processing analysis techniques: horizontal strain influence area and maximum shear strain influence area. Multiple passages of two knownweight trucks were used to calibrate the bridge response under truck traffic load. Truck data from the traffic stream was then analyzed for weight prediction and the results compared to truck weight data measured at a nearby weigh station.

\section{THEORETICAL BACKGROUND}

A simply supported beam idealization of a single span bridge of length $L$ is presented in Figure 1a. The bridge longitudinal axis is parallel to $\mathrm{x}$-axis. An individual moving point load $P$, for example a single vehicle axle, travels over the bridge inducing internal reactions. The resulting shear force and bending moment diagrams can be constructed providing the shear force and bending moment at each location $x$ for load $P$ at a fixed point (Figure 1b). Additionally, the shear force and bending moment influence lines (IL) can be constructed providing the shear force and bending moment at a fixed point for the load $P$ applied at each location $x$ over the beam. Considering a strain sensor placed at $x=\delta L$, the corresponding theoretical influence lines are presented in Figure 1c. The dynamics of the load and response of the beam are not included.

If the vehicle travels at constant velocity $v=x / t$ over the bridge, the Figure 1 influence lines can be expressed as a function of time,. Considering that the beam remains elastic, the superposition principle can be applied for multiple point loads, $P_{i}$, i.e. axles. Figure 2 shows an example of a $355.8 \mathrm{kN}$ 
(80 kips) five-axle vehicle, with axle weights and locations as shown in Figure 2c, traveling at $50 \mathrm{~km} / \mathrm{h}$ (31 mph) crossing a 27.4-m-long (90 ft) bridge with the sensor placed at $\delta=0.50, \delta=0.10$ and, $\delta=0.01$. Individual axle bending moment and shear forces responses (representing axles, Figure 2a) are presented, as a function of time instead of location, as well as their superposition (representing the truck, Figure $2 \mathrm{~b}$ ). For a small $\delta$ (a close-to-end position, for instance $\delta=0.10$ ), the negative peak of the shear force response is very small compared to the maximum positive amplitude, and the area under the shear force increases, similar to the bending moment measured at midspan $(\delta=0.50)$.

From force equilibrium, the bending moment and shear force in Figures $2 \mathrm{a}$ and $2 \mathrm{~b}$ result in horizontal (parallel to $\mathrm{x}$-axis) and shear stresses (Beer, et al., 2020), and from Hooke's Law the stresses can be written as strains - a quantity that can be measured on the bridge with sensors. As such, the horizontal and shear strain time histories, called the response waves ( $R_{\varepsilon}$ and $R_{y}$ respectively), will be proportional to the bending moment and shear force responses shown in Figure $2 \mathrm{~b}$.

Using the concept of influence area (Ojio \& Yamada, 2002) the area under the response waves (denoted $A_{\varepsilon}$ and $A_{\gamma}$, here to distinguish between horizontal strain, $\varepsilon$, and shear strain, $\gamma)$ is equal to the product of the gross vehicle weight $\left(G V W=\sum_{i=1}^{N} P_{i}\right)$ of an $N$-axle truck, and the integral of the normalized strain function $\left(f_{\varepsilon}(t)\right.$ and $\left.f_{\gamma}(t)\right)$ such that:

$$
A_{k}=\int_{t_{0}}^{t_{2}} R_{k}(t) v d t=\int_{t_{0}}^{t_{2}} \sum_{i=1}^{N} P_{i} f_{k}(t) v d t=G V W \int_{t_{0}}^{t_{2}} f_{k}(t) v d t \quad k=\varepsilon, \gamma
$$

For a fixed axle spacing and relative weights of axles, the integral in equation (1) is a constant

$$
C_{k}=\int_{t_{0}}^{t_{2}} f_{k}(t) v d t \quad k=\varepsilon, \gamma
$$

which allows for equation (1) to be rewritten as

$$
A_{k}=(G V W) C_{k} \quad \text { or } \quad C_{k}=\frac{A_{k}}{G V W} \quad k=\varepsilon, \gamma
$$

For two different trucks (one with known weight and one with unknown weight) with the same axle spacing and relative axle weights $C_{k}$ is constant and

$$
C_{k}=\frac{A_{k, k}}{G V W_{k}}=\frac{A_{k, u}}{G V W_{u}} \quad k=\varepsilon, \gamma
$$

which can be rearranged to provide

$$
G V W_{u}=\left(\frac{G V W_{k}}{A_{k, k}}\right) A_{k, u}=\beta_{k} A_{k, u} \quad k=\varepsilon, \gamma
$$

where $\beta_{k}=G V W_{k} / A_{k, k}$ is the calibration constant of the known vehicle and can be determined from measured strains and a measured GVW from a static scale (or otherwise). This calibration constant is dependent of the number and spacing of the truck axles.

a)

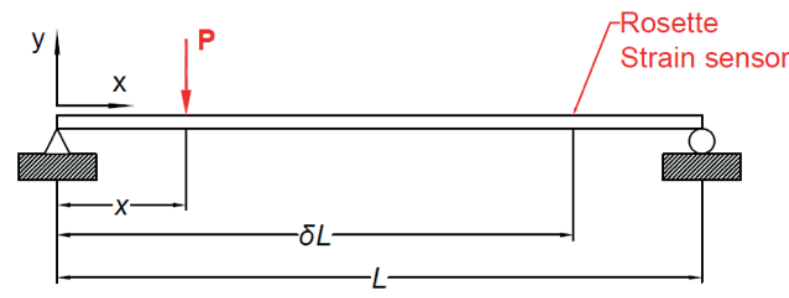

Shear Force Diagram

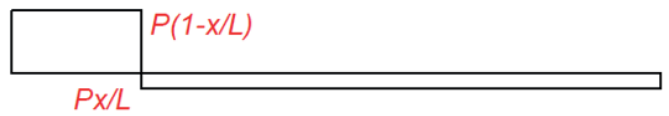

b)

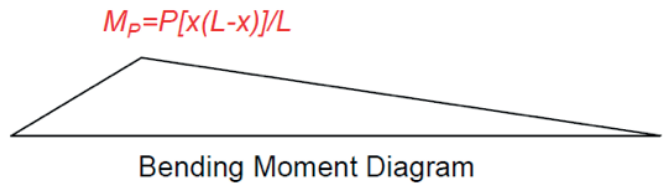

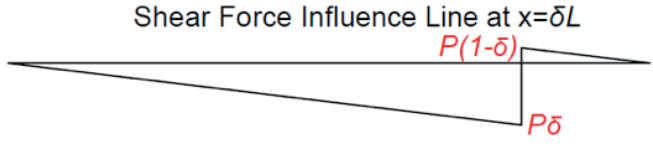

c)

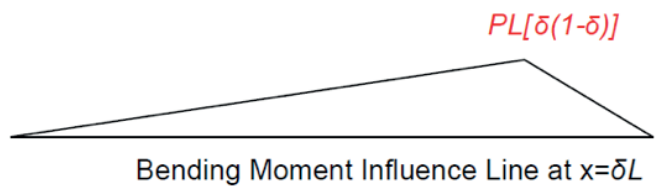

Figure 1. a) simply supported beam model, b) moment and shear force diagrams due to a single concentrated load, and c) influence lines at the sensor location. 

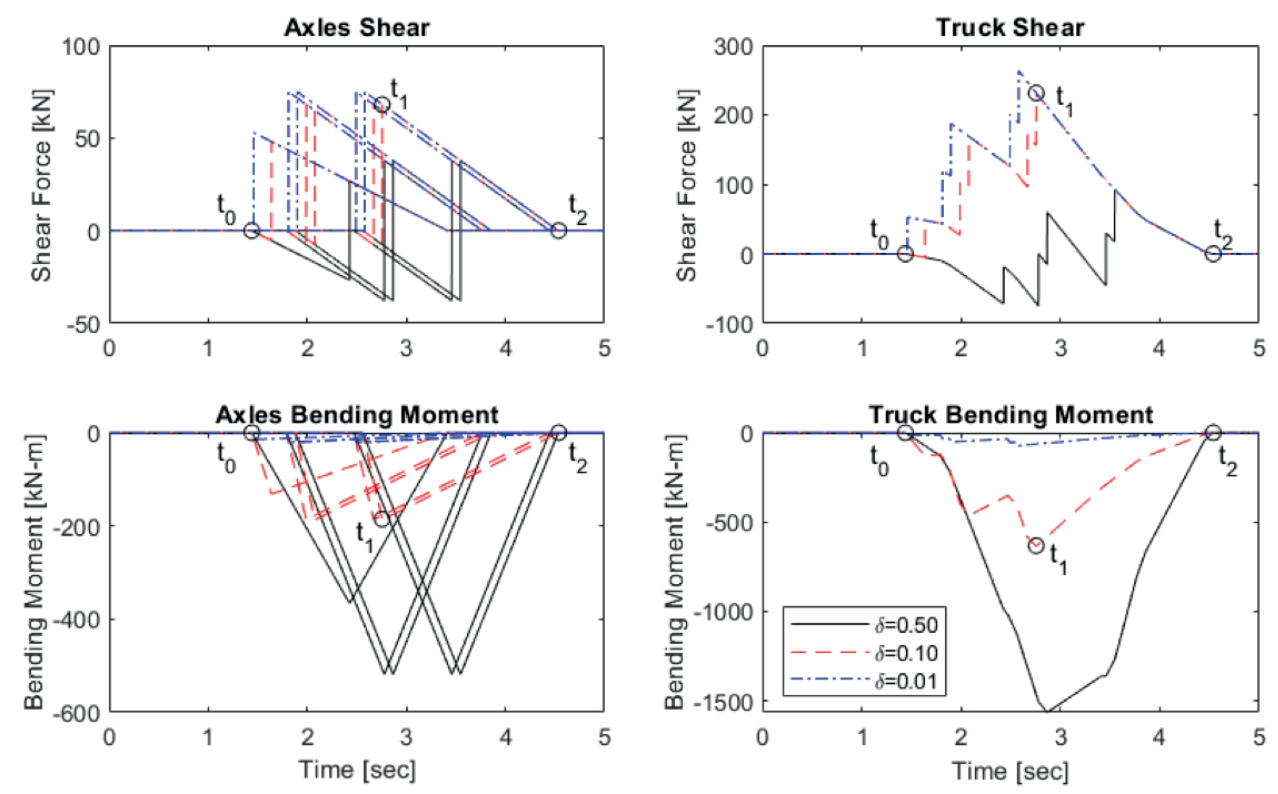

a)

b)

c)

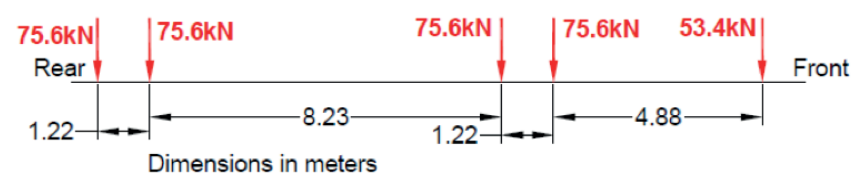

Figure 2. Five-axle truck bending and shear response example, a) single axle individual response,

b) truck response, and c) axle weight and axle separation.

The areas under the shear response waves are determined from the measured time histories of the strain as

$$
A_{k}=v \int_{t_{0}}^{t_{2}} R_{k}(t) d t
$$

where the velocity, assumed to be constant over the bridge, is removed from the integral.

Of interest in this research is the observation that as the location of the strain sensor nears the end of the beam $(\delta \approx 0)$, the area under the horizontal bending response wave approaches zero. This raises issues associated with the signal to noise measurement and potential inaccuracies as the sensors are located in more practical and feasible locations (Lobo \& Christenson, 2016) under the bridge (as opposed to the midspan which provides for the largest area but maybe more challenging installation). Alternatively, the area under the shear strain response wave has a maximum value at $\delta=0$. However, the area under the shear strain approaches zero at a sensor location near the midspan $(\delta \approx 0.5)$. This is observed in Figure 3. In this paper, the authors propose the use of the maximum shear strain to provide a more robust influence area BWIM approach.

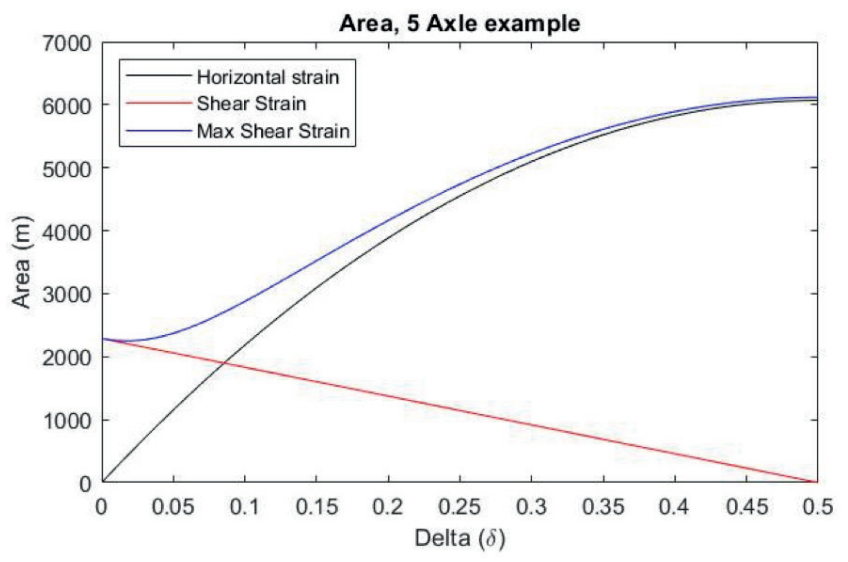

Figure 3. Area under horizontal strain, shear strain and maximum shear strain response waves in function of the sensor location.

Experimental horizontal strain and shear strain, i.e. the strain functions, can be obtained from a rectangular rosette array by applying the following equations from Popov (1990):

$$
\begin{gathered}
f_{\varepsilon}(\mathrm{t})=\varepsilon_{0^{\circ}}(\mathrm{t}) \\
f_{\gamma}(t)=\gamma_{x y}(\mathrm{t})=2 \varepsilon_{45^{\circ}}(\mathrm{t})-\left(\varepsilon_{0^{\circ}}(\mathrm{t})+\varepsilon_{90^{\circ}}(t)\right)
\end{gathered}
$$




$$
f_{\gamma_{\max }}(t)=\gamma_{\max }(t)=2 \sqrt{\left(\frac{\varepsilon_{0^{\circ}(t)-\varepsilon_{90^{\circ}}(t)}}{2}\right)^{2}+\left(\frac{\gamma_{x y}(t)}{2}\right)^{2}}
$$

where $\varepsilon_{00}(t), \varepsilon_{450}(t)$, and $\varepsilon_{900}(t)$ are the horizontal (parallel to $\mathrm{x}$-axis), inclined, and vertical (parallel to $\mathrm{y}$-axis) strain measurements.

Evaluating equation (9) for maximum shear strain, the area under the maximum shear strain curve can be also calculated (blue line in Figure 3). Given that equation (9) gives always a positive value the area under the maximum shear strain response wave is not null and it follows the horizontal strain area trend shown on Figure 3.

Equation (9) can then be used with equations (1) and (5) to determine the gross vehicle weight from the shear strain. Note, if the sensor rosette is placed at the neutral axis of the composite beam and deck system $\left(\varepsilon_{0 \circ}=0\right)$ and the local strains due to the point load are ignored $\left(\varepsilon_{900}=0\right)$ then $y_{x y}=y_{\max }$. However, to account for uncertainty in the location of the neutral axis due to geometry and/or composite action of the deck with the girders and possible vertical strain due to axle loads, the maximum shear stress from equation (9) is assumed to provide a more complete measurement of strain in the beam and allows for a broader range of $\delta$.

For both horizontal and shear strain methods that use the influence area, the velocity is critical and can be determined in various ways. In this study, the velocity was estimated by dividing the distance from the sensor location to the end of the bridge by the time it takes the last axle to move from the sensor location to the bridge abutment. The last axle is over the sensor location at time $t_{1}$ in Figure 2, which corresponds to the maximum peak in the wave response, and it leaves the bridge at time $t_{2}$. With the difference between $t_{2}$ and $t_{1}$ and the distance $L(1-\delta)$, the velocity $v$ is calculated (LoboAguilar, 2018) as

$$
v=L(1-\delta) /\left(t_{2}-t_{1}\right)
$$

\section{FIELD TEST DESCRIPTION}

A field test was performed over two days in December 2019, on a single-span steel girder bridge located in the Guanacaste, Costa Rica (Figure 4a). The Desjarretado River Bridge is part of the Pan American Highway that extends from Prudhoe Bay, Alaska to Ushuaia, Argentina. This strategic route is included in the Costa Rican High Capacity Highway Network. This bridge is shown in Figure 4d, and its main characteristics are listed in Table 1. Also shown in Figure 4c is the location of a Weigh Station operated by the Costa Rican Transportation
Authorities and used in this study to validate BWIM performance. The distance between the bridge and the weigh Station is $12.4 \mathrm{~km}$ (7.8 mi, Figure $4 \mathrm{~b})$.

\begin{tabular}{|c|c|}
\hline \multicolumn{2}{|c|}{ Table 1. Desjarretado River Bridge description } \\
Location & $\begin{array}{c}\text { Las Juntas de Abangares, } \\
\text { Guanacaste, Costa Rica }\end{array}$ \\
\hline Length & 27.9 m (91.5 ft.) \\
\hline Total width & 9.16 m (30.0 ft.) \\
\hline Number of Spans & 1, single span \\
\hline Traffic directions & 2 (1 per lane) \\
\hline Superstructure & Composite steel I beam \\
\hline Main girders / section & $4 /$ W36x260 \\
\hline Deck thickness & 179 mm (7 in) reinforced concrete slab \\
\hline Design year / construction & 1951 / 1959 \\
\hline Design code / live load & AASHO 1949 / H15-S12-44 \\
\hline
\end{tabular}

Two calibration trucks were used for this study, as pictured in Figure 5. One of them was a two-axle light duty box truck that belongs to the University of Costa Rica (labeled here as UCR truck), while the other one was a three-axle dump truck that was hired for the test (labeled here as dump truck). Figure 5 shows axle spacing and weights of these two trucks, as measured with a portable scale at the beginning of testing.

The bridge was instrumented with a Bridge Diagnostics Inc. (BDI) STS4 portable monitoring system, which included measurements from strain sensors and accelerometers at a sampling rate of $100 \mathrm{~Hz}$. However, in this study, only data from three strain sensors are considered. As shown in the general layout of Figure 6a, these three strain gages were located at the web of the second most downstream girder of the bridge, using a rectangular rosette configuration (denoted here as R1, and presented in Figure 6b). Figure 6a shows traffic directions over the bridge: Northbound to San Jose and Southbound to Liberia. The sensor location corresponds to a location closer to Southbound traffic lane. Also, the rosette was located at a distance of $3.50 \mathrm{~m}$ (corresponding to $\delta=0.13$ ) from the north end of the bridge. Regarding Figure 3, the location of the sensor at $\delta=0.13$ allows to compare the GVW based on the areas of horizontal strain, shear strain and maximum shear strain, avoiding a close to support location or a center-length location, which will result in small values of shear strain area or horizontal strain area, respectively.

Besides, a close to the beam-end location was selected to ease the installation and maintenance work of the sensors. Locations close to the center of the beam may require scaffolding, even if the river is dry, and may need more wiring. Finally, the rosette was placed close to the centroid of the 
cross section of the simple girder, in order to avoid the neutral axis of the composite section, and therefore capturing both bending and shear strains. A $\delta=0.13$ location was selected instead of $\delta=0.87$, due to the shear strain negative peak, which can affect the time $t_{2}$ identification in the experimental response wave. For this reason, it is preferred that the strain sensors are placed in the entering end of the traffic line.
Truck data from the traffic stream was also collected on two consecutive days, for a total sampling time of three hours. In addition, Southbound traffic was video-recorded at the Bridge and Weigh Station in order to compare BWIM results to static measurements taken at a nearby Weigh Station provided by the Costa Rican Transportation Authorities. This is shown in Figure 7, where truck plate numbers were covered and the calibration truck passages are labeled.

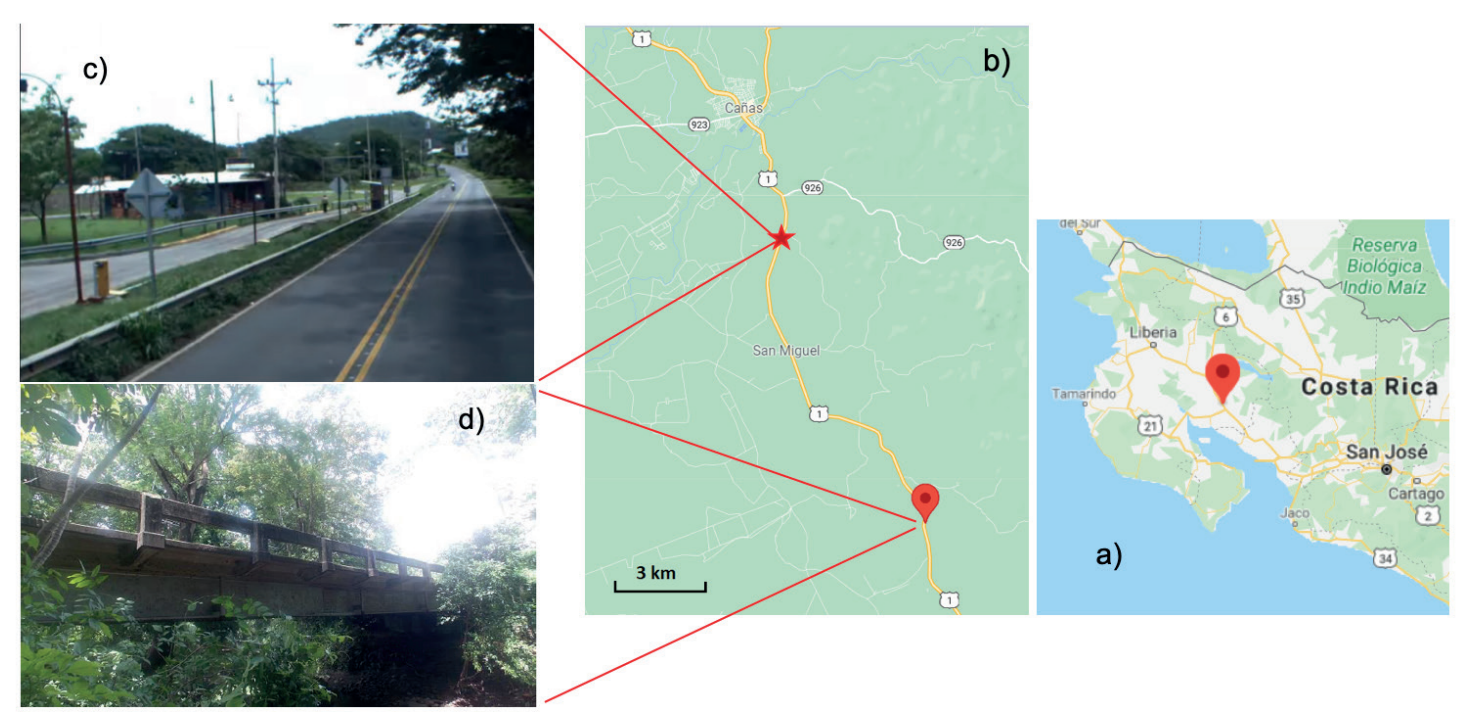

Figure 4. a) Desjarretado River Bridge location, b) Route 1 map including the bridge and weigh station locations, c) Weigh Station, and d) Desjarretado River Bridge side view (Alvarez-Gonzalez, et al., 2019; Google Maps, 2021; UGERN, LanammeUCR, 2018).
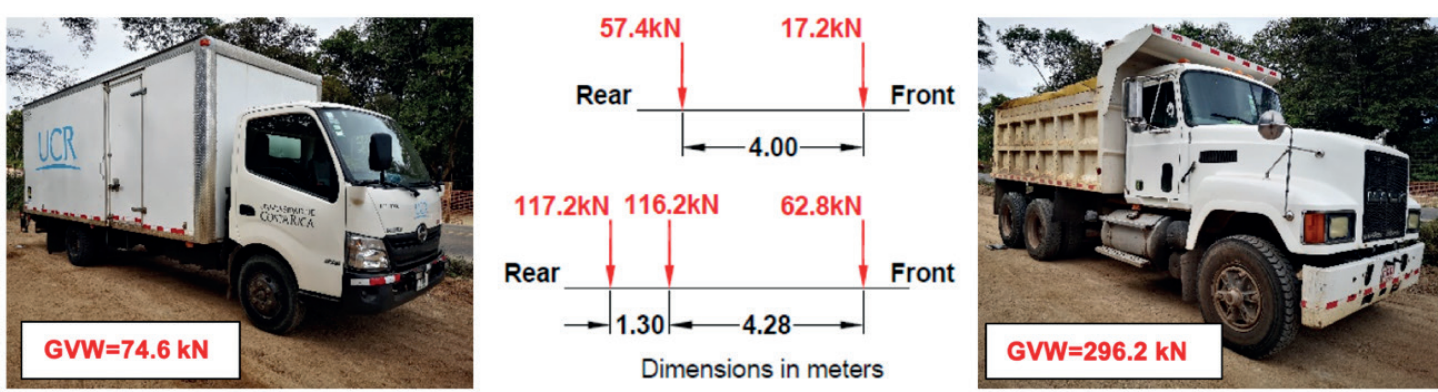

Figure 5. Axle spacing and loads of the UCR truck (left/upper) and the dump truck (right/lower).

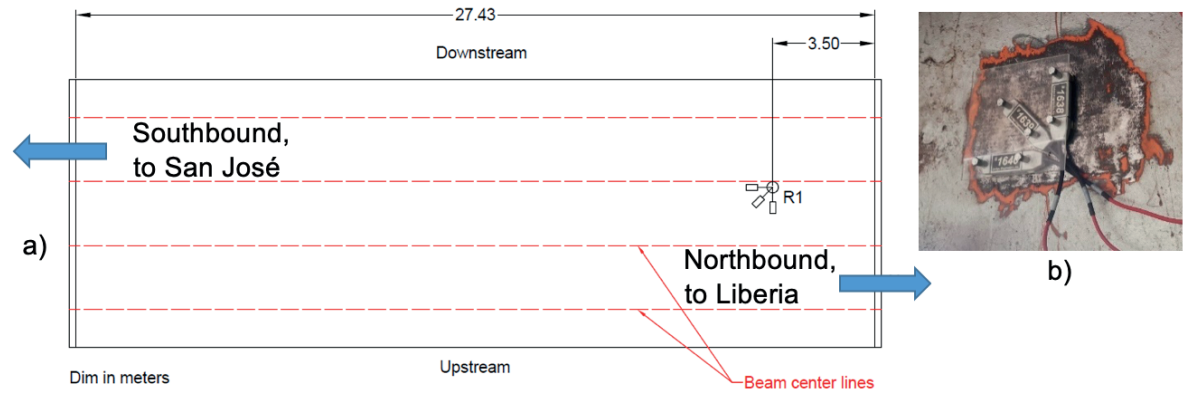

Figure 6. a) Schematic layout of the location of the sensors and, b) Rosette R1. 


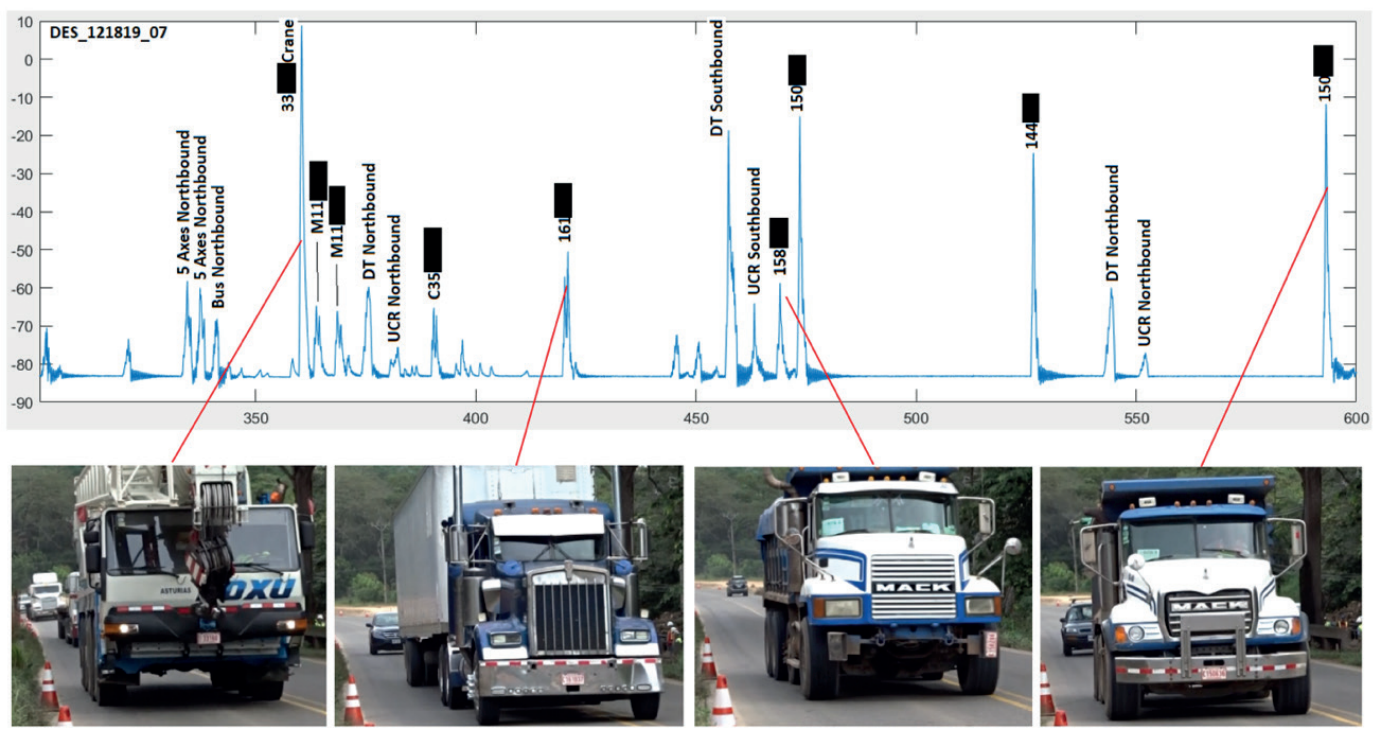

Figure 7. Trucks from the traffic stream raw data time histories examples.

\section{RESULTS}

\subsection{Calibration}

In general, only the passages where these trucks traveled alone north to south over the bridge were considered for calibration. Using this criteria, 45 passages of the UCR's box truck and 18 passages of the dump truck were considered. The recorded horizontal strains of such passages are shown in Figure 8. This data was filtered in MATLAB with an eight-pole low pass Butterworth filter with a cutoff frequency of $15 \mathrm{~Hz}$. The theoretical shape of the influence response waves, excluding dynamics of the bridge and the bridge-truck interaction, are included in Figure 8 for comparison purposes. The height of the theoretical response wave was manually adjusted to the highest peak observed on experimental data for geometrical comparison purposes.

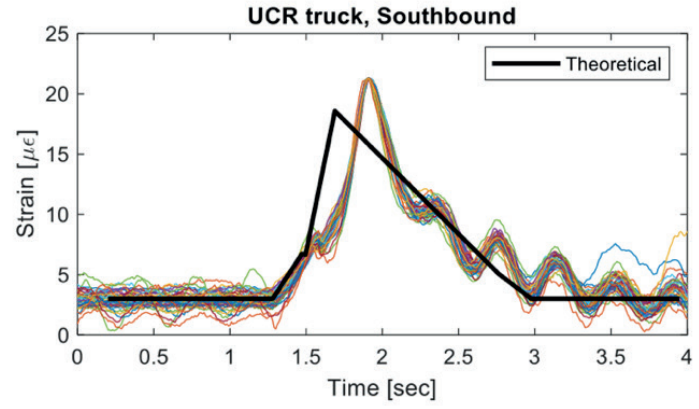

The velocity of the calibration trucks were calculated using equation (10). In this equation, the exact moment at which the truck exits the bridge, denoted here as $t_{2}$, was selected manually according to the authors' judgement as the $2.4 \mathrm{~Hz}$ bridge dynamics proved challenging to automate this selection. Conversely, time $t_{1}$ was chosen using the MATLAB function findpeaks().

From the application of equations (7), (8) and (9), the maximum shear strain was calculated for each passage. Figure 9 presents the corresponding maximum shear response waves; the results are consistent like in Figure 8. The shape of the horizontal and maximum shear waves is very similar, as commented above, from the theoretical responses of Figure 2.

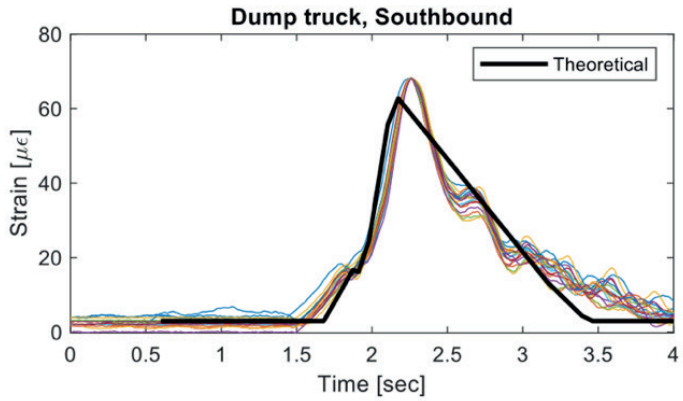

Figure 8. Horizontal strain response waves induced by the calibration trucks and theoretical-shape influence line. 

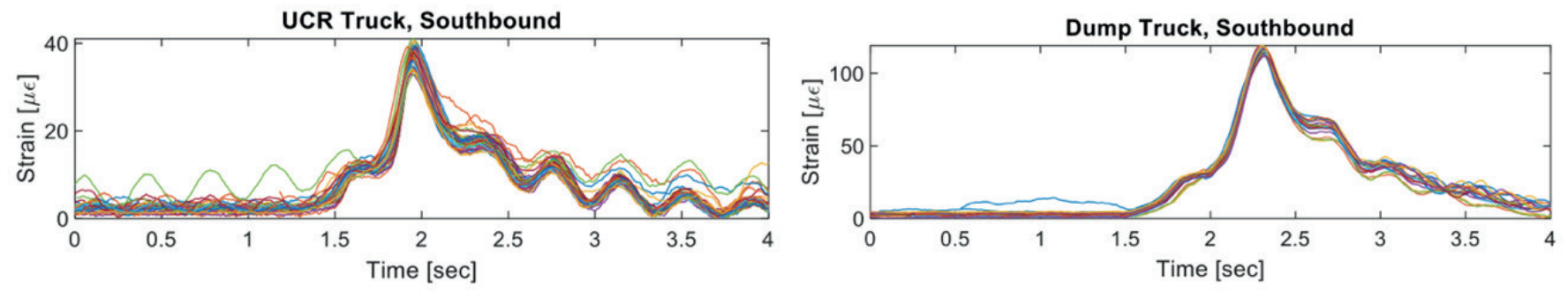

Figure 9. Calculated maximum shear strain response waves induced by calibration trucks

From Figure 9, the maximum shear strain is around $40 \mu \varepsilon$ for the UCR's box truck and $120 \mu \varepsilon$ for the dump truck, compared to the horizontal strain maximum values around $20 \mu \varepsilon$ and $65 \mu \varepsilon$ respectively, i.e. $y_{\max } / \varepsilon$ equals 2.0 and 1.85 respectively. A theoretical verification based on static moments and shears calculated from the known weights of the calibration trucks at the sensor location was performed. From the moments and shears, and taking into account the geometry of the section, values of theoretical horizontal strain and maximum shear strain were calculated. Varying the tributary width of the concrete slab, this static theoretical result shows similar $y_{\max } / \varepsilon$ ratio from 1.33 to 1.74 comparable to 2.0 obtained with the dynamic experimental data. If the sensor rosette is placed closer to the midspan of the bridge, the ratio $y_{\max } / \varepsilon$ will be less than 1 and it would be appropriate to simply use the single horizontal strain measurement. However, if the sensor rosette is placed closer to the bridge end, the ratio $y_{\max } / \varepsilon$ will be higher and it may be more advantageous to use shear strain.
Using velocities from equation (10), the calibration constants $\beta_{k}(k=\varepsilon, y)$ for both horizontal and shear strain response waves, were calculated for each one of the passages, using equation (5). The statistics are summarized in Table 2.

Using the mean values of the calibration constants from Table 2, the weights of the calibration trucks were calculated for each individual passage. Figure 10 shows a box plot of the calibration results. Outliers were discarded around $2^{\text {nd }}$ and $98^{\text {th }}$ percentiles. The blue box includes $50 \%$ of the data delimited by $25^{\text {th }}$ and $75^{\text {th }}$ percentiles, the red line is the median value, the black circle is the average and the red circle is the average plus-minus one standard deviation. The horizontal strain results show less dispersion. The information of Figure 10 was analyzed in histograms of the GVW and the absolute error percentage, using the bin number from the Sturges' rule, the Chi-Square and the Kolmogorov-Smirnov goodness-offit tests show that a normal distribution for the GVW and a semi-log distribution for the absolute error are suitable. From Figure 10, the distribution can be supposed symmetrical because the average and the median are near.

\begin{tabular}{|c|c|c|c|c|}
\hline & \multicolumn{2}{c|}{ Table 2. Calibration constants $\beta$ calculated [kN/m] } \\
Truck & \multicolumn{2}{c|}{ Horizontal strain method $\beta_{\varepsilon}$} & \multicolumn{2}{c|}{ Shear strain method $\beta_{\gamma}$} \\
& Sample mean & St. Dev. & Sample mean & St. Dev. \\
\hline UCR & 183.11 & 11.36 & 340.22 & 26.98 \\
\hline Dump & 673.40 & 28.48 & 1162.52 & 53.98 \\
\hline
\end{tabular}
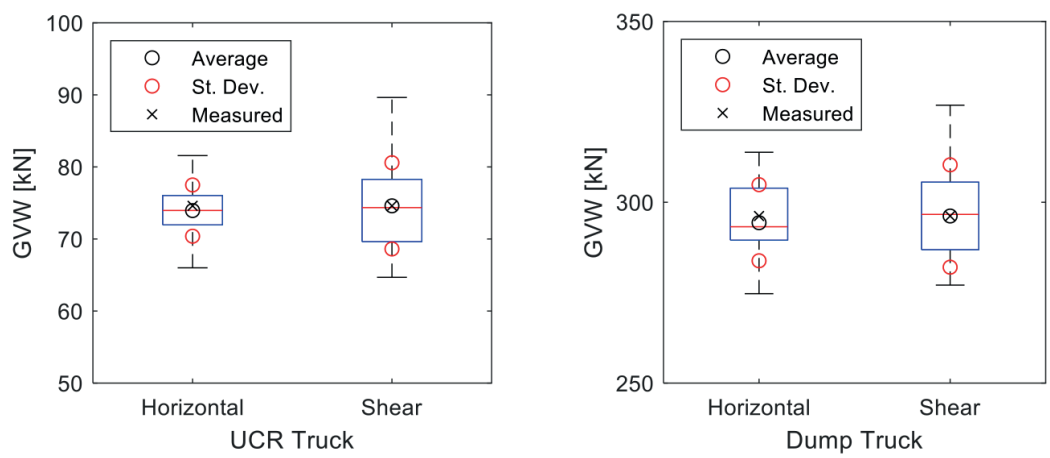

Figure 10. Calibration results for UCR truck and Dump truck 
For reference purposes, ASTM E1318 standard defines the functional performance requirements for WIM systems that predicts the GVW of vehicles. The standard defines that 95\% of the GVW values produced by the WIM system must be within the tolerance limit. The tolerance limit for GVW is $10 \%$ for WIM Systems Type I and 15\% for WIM Systems Type II. In this work, an ASTM E1318 calibration test was not performed strictly, because the vehicle class and velocities used in this study do not fulfill the standard. However, Table 3 summarizes the obtained accuracy with the ASTM E1318 approach as a reference. In that case, the calibration results can fulfill the $95 \%$ compliance requirement for the tolerance $\pm 15 \%$ limit predicting GVW.

\section{Table 3. Percentage of passages within the tolerance}

limit of $\pm 15 \%$ respect the known calibration GVW

\begin{tabular}{c|c|c|c|} 
Truck & $\begin{array}{c}\text { Number of } \\
\text { passages }\end{array}$ & $\begin{array}{c}\text { Horizontal strain } \\
\text { method }\end{array}$ & $\begin{array}{c}\text { Shear strain } \\
\text { method }\end{array}$ \\
\hline UCR & 45 & 95.6 & 98.8 \\
\hline Dump & 18 & 100 & 100 \\
\hline
\end{tabular}

\subsection{Traffic Weight Prediction}

Comparing the video data with the permanent weigh station data, 90 southbound truck crossings from the traffic stream data were available for weight prediction. With these 90 truck events, a regression analysis was conducted, in order to verify the accuracy of the results. The charts of Figure 11 show the results where one outlier was eliminated using standardized residual analysis. In both cases, the regression analysis show good agreement between static and BWIM measurements, since both the slopes and the $R^{2}$ determination factor are close to unity. In general, the closest slope to unity is based on the UCR Box truck calibration constants, and the best results are based on the area of the horizontal strain.

Figure 12 shows the histogram of the 90 trucks from weigh station data, which were identified from the video recording, as well as the results of the GVW prediction histograms. The results of the GVW prediction for trucks under $200 \mathrm{kN}$ are varied. In all cases, trucks over $200 \mathrm{kN}$ have similar results. Applying a two-sample Kolmogorov-Smirnov test with 5\% significance level to the histograms of the Figure 12, the GVW predictions are representative of the Weight Station data, with p-values above 0.965 . This result is acceptable for overweighttruck identification.

Table 4 presents the percent difference calculation between the traffic BWIM's GVW prediction and the GVW provided by the weigh station data. The results do not fulfil the $95 \%$ compliance requirement for the tolerance $\pm 15 \%$ limit predicting GVW. The best result is provided for the horizontal strain influence area method, that reaches the $77.8 \%$ compliance for the $\pm 15 \%$ tolerance limit.
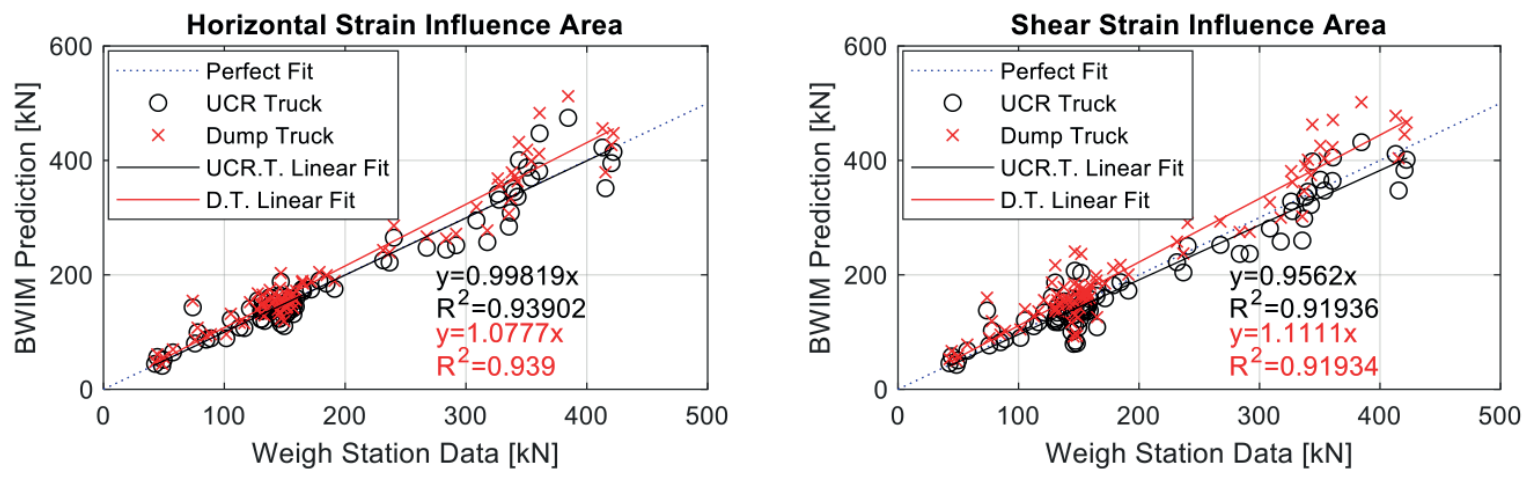

Figure 11. Results for horizontal strain influence area and shear strain influence area

for two calibration trucks and two velocity estimations. 

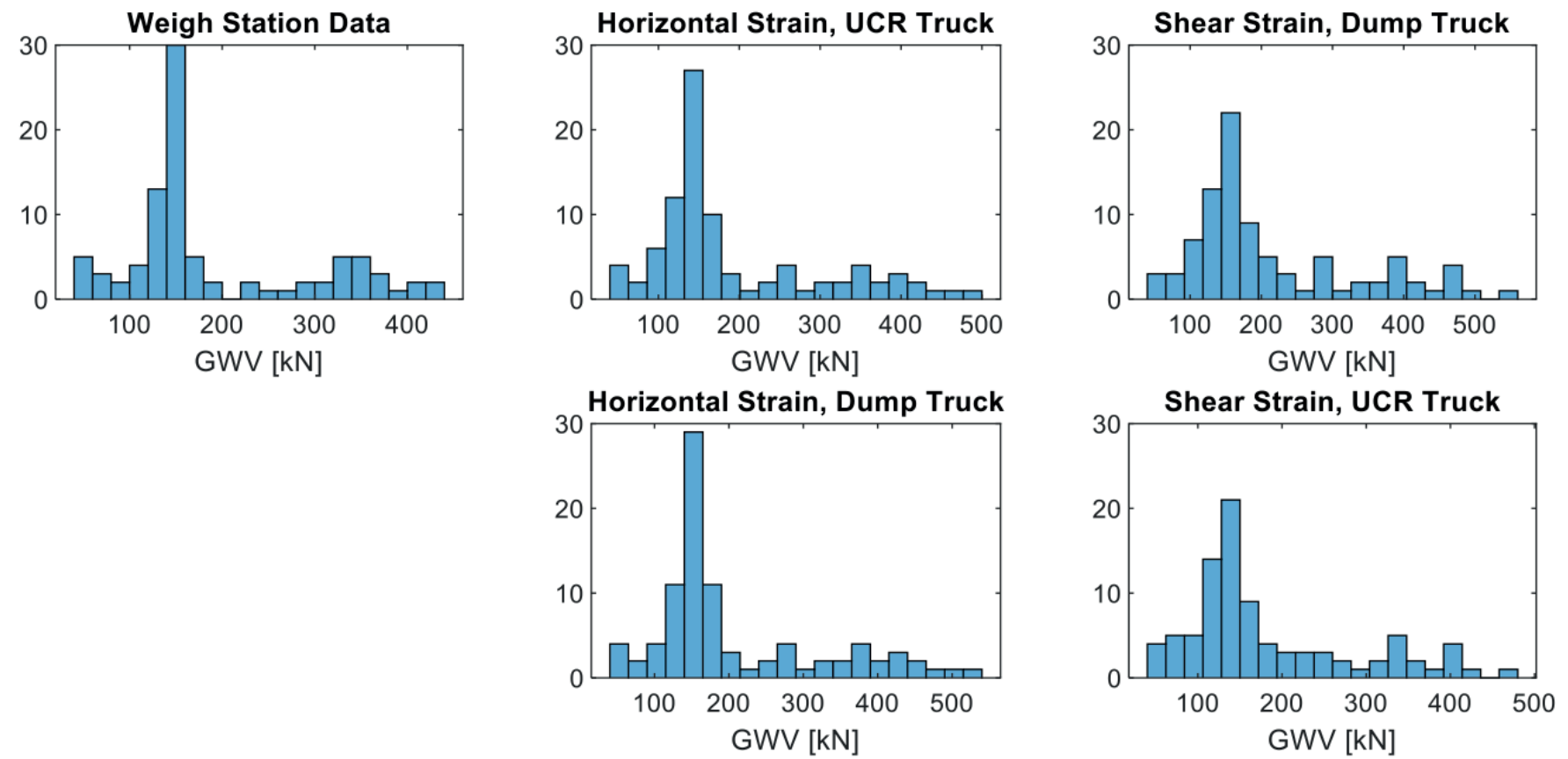

Figure 12. Random data and prediction results histograms (90 passages).

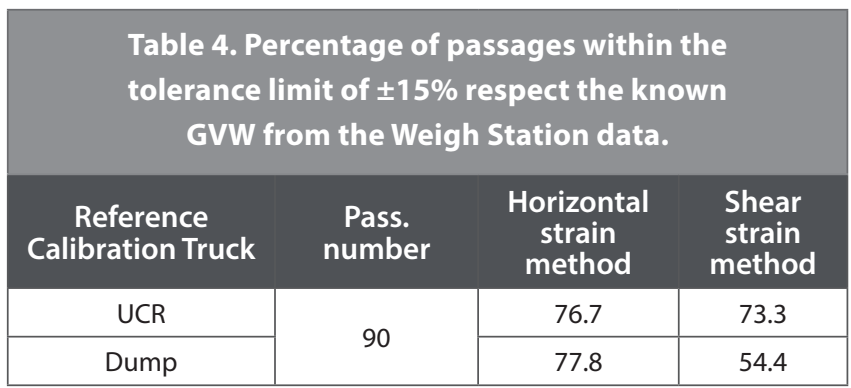

\section{CONCLUSIONS}

In this paper, the implementation of a BWIM technique in Costa Rica is presented. Two post-processing methods based on the influence area method were used. In the first one, the influence area is based in the horizontal strain measurement which is typical of previous BWIM methods. The second approach takes advantage of the fact that the response wave of the maximum shear strain approaches to the horizontal strain's response wave in the full length of the bridge, which can provide for increased safety and decreased cost and time for installation.

The best results of GVW prediction are provided from horizontal strain influence area method. In the best case, the operative estimation accuracy reaches $78 \%$ with a $\pm 15 \%$ tolerance limit. Calibration results show an accuracy between
95.6 and $100 \%$. It is noteworthy to mention that the traffic over the bridge was running in two directions.

The advantage of this result is that a single sensor system can be used in short bridges, instead of rosette arrays, in a possible operative phase of BWIM, minimizing the sensors cost and the amount of data to process for the bridge managers. The installation of one single horizontal sensor is not recommended for values of $\delta<0.10$ according the analysis presented in Figure 3.

The maximum shear strain method is anticipated to work better for longer bridges where the sensor is installed close to the bridge end; it is shown have to provided comparable results as presented in Figure 3. When the shear strain method is selected, it is recommended to place the sensor closer to the abutment as possible to minimize the magnitude of the shear strain negative peak. Furthermore, as discussed earlier, it is preferred to place the sensors in the incoming traffic end of the traffic line.

Due to the interaction of vehicles traveling in opposite directions, it is recommended to place one sensor per lane, which increase the cable requirement. Therefore, a future research effort should be studying the influence of two traffic directions traveling over the bridge, given the high quantity of those bridges in service in Costa Rica. Another future research effort should focus in BWIM systems implementation in 
single-span reinforced and/or prestressed concrete girder structures, given that around $80 \%$ of the bridges in Costa Rica are built with these materials (MOPT, CONAVI, 2021).

Finally, for a future implementation of this technology in Costa Rica, it is necessary to define a group of strategic bridges placed in the most important heavy transportation routes.

\section{ACKNOWLEDGEMENT}

The authors express their gratitude to University of Costa Rica, specially to the University Environment of Advanced Studies (UCREA) for sponsor this research. The authors acknowledge partial support from the University of Connecticut.

The authors appreciate LanammeUCR's personnel for the support in the field trip (Rolando Castillo, Esteban Villalobos, Hellen Garita, Mauricio Araya, María José Rodríguez, Alejandro Carvajal, Luis Guillermo Vargas, Sergio Álvarez, Melissa Rojas, Francisco González, Greivin Ceciliano, Catalina Vargas, and Jaime Allen).

\section{REFERENCES}

Allen, J., Vargas, C., Hernández, H. (2014). Determination of the Quantity and Location of Weigh Stations in the Costa Rican National Highway Network. LanammeUCR Report No. LM-PIGM-02-2014. pp. 10. (In Spanish)

Alvarez-Gonzalez, S. G., Garita-Duran, H. A., Villalobos-Vega, E., Castillo-Barahona, R. (2019). Condition Evaluation of Desjarretado River Bridge, National Route No.1. Report No. LMPIE-UP-P05-2019. Structural Engineering Program. National Laboratory of Materials and Structural Models. University of Costa Rica. (In Spanish)

ASTM Standard E1318, 09 (2017), Standard Specification for Highway Weigh-In-Motion (WIM) Systems with User Requirements and Test Methods, ASTM International, West Conshohocken, PA, 2017, DOI: 10.1520/E1318-09R17, www.astm.org.

Beer, F., Johnston, E., DeWolf, J., Mazurek, D. (2020) Mechanics of Materials. Eight edition. McGraw Hill. ISBN-13: 9781260113273.

CONAVI (2017) Public bidding 2017LN-000008-0006000001 for the design and construction of "La Julieta" station. National Road Management Council, Costa Rica.

Froseth, G., Ronnquist, A., Cantero, D., Oiseth, O. (2017). Influence line extraction by deconvolution in the frequency domain. Computers and Structures. http://dx.doi.org/10.1016/j. compstruc.2017.04.014

Hitchcock, W.A., Uddin, N., Sisiopiku, V., Salama, T., Kirby, J., Zhao, H., Toutanji, H., Richardson, J. (2012) Bridge Weigh-In-Motion System Testing and Evaluation. Report Number 07212, University Transportation Center of Alabama.
Lechner, B., Lieschnegg, M., Mariani, O., Pircher, M. (2013) Detection of Vehicle Data in a Bridge Weigh-In-Motion System. Modern Traffic and Transportation Engineering Research, Vol. 2, pp. 153-161.

Lobo-Aguilar, S., Christenson, R. E. (2016). Numeric Study of the Influence of the Signal Noise, Location of the Sensors and Sampling Rate on the Strain-Only BWIM Method. Métodos y Materiales. Vol. 6, Num. 1, pp. 34-43. ISSN: 2215-4558.

Lobo-Aguilar, S. (2018). Advances in Smart Structure Technologies for Civil Infrastructures. Doctoral Dissertations. 1870. https:// opencommons.uconn.edu/dissertations/1870

MOPT, CONAVI (2021). Bridge Management System (SAEP). Ministry of Public Works and Transportation, National Roads Council. San José, Costa Rica. http://saep.conavi.go.cr:9080/SAEP_ CONAVI_Web/login.faces

Muñoz, E. Gómez, D., Núñez, F., Florez, C. (2011). Determinación de Cargas Dinámicas de Camiones Pesados que Transitan en un Puente Basado en Algoritmos Genéticos e Instrumentación. Revista Ingeniería y Construcción, Vol. 26 pp. 321-352. http:// dx.doi.org/10.4067/S0718-50732011000300005

O’Brien, E.J., Znidaric, A., Ojio, T. (2008) Bridge Weigh-In-Motion Latest Developments and Applications World Wide. International Conference of heavy Vehicles, Paris, pp. 25-38.

Ojio, T., Yamada, K. (2002) Bridge Weigh-In-Motion System Using Stringer of Plate Girder Bridges. Pre-proceedings of the International Conference on Weigh-In-Motion, Orlando, Florida, pp. 209-218.

Popov, E. P. (1990). Engineering Mechanics of Solids. Second Edition. Pearson.

Sanabria-Sandino, J., Barrantes-Jiménez, R. (2019). Evaluation of the Paved National Network of Costa Rica. Report LM-PIUGERVN-004-19. Transportation Engineering Program. National Laboratory of Materials and Structural Models. University of Costa Rica. (In Spanish).

Wall, C. J., Christenson, R. E., McDonnell, A. H., Jamalipour, A. (2009). A Non-Intrusive Bridge Weigh-in-Motion System for a Single Span Steel Girder Bridge Using Only Strain Measurements. Report No. CT-225-3-09-5. Office of Research and Materials. Bureau of Engineering and Construction. Connecticut Department of Transportation.

Zheng, X., Yang, D. H., Yi, T. H., Li, H. N., Chen, Z. W. (2019). Bridge Influence Line Identification Based on Regularized Least-Squares QR Decomposition Method. Journal of Bridge engineering. ASCE. DOI: 10.1061/(ASCE)BE.1943-5592.0001458 